\title{
EMPREENDEDORISMO DE MULHERES ARTESÃS: caminhos entre o capital social e a autogestão
}

\section{ENTREPRENEURSHIP OF WOMEN ARTISANS: paths between social capital and self-management}

\author{
Patrícia Morais Azevedo* \\ Maristela Oliveira de Andrade**
}

\begin{abstract}
Resumo
O presente artigo tem como objetivo debater o papel da mulher artesã no contexto do empreendedorismo feminino, tendo em vista que ela está se posicionando, cada vez mais, no mercado de trabalho com a abertura de seu próprio negócio, seja individual ou de forma coletiva, como acontece nas associações e cooperativas de artesãs, agricultoras, entre outras. Busca-se entender o empreendedorismo feminino sob a perspectiva dos conceitos de capital social, participação e autogestão, tomando como base a experiência do trabalho desenvolvido pelas mulheres artesãs que integram a Associação Mãos que se Ajudam, no município de Lucena/PB. A metodologia de trabalho baseou-se na pesquisa bibliográfica e de observação participante, assim como na realização de entrevistas semiestruturadas e aplicação de questionários junto aos membros da Associação (presidente, cocadeiras e artesãs da fibra do coco). Também foram entrevistados gestores públicos, participantes diretos do processo constitutivo da referida Associação. Por fim, verificou-se que o empreendedorismo feminino pesquisado resultou em participação e acúmulo de capital social das artesãs na esfera produtiva da cocada, porém, na esfera da autogestão, os resultados se mostraram insatisfatórios. A baixa escolaridade das mulheres, assim como a experiência anterior delas no mundo do trabalho, circunscrita às atividades domésticas seriam fatores a dificultarem a compreensão do papel de empreendedoras. A inserção das mulheres na Associação, em busca de uma fonte de renda, favoreceu uma identificação com o trabalho assalariado e está, portanto, distante da concretização dos objetivos da autogestão.
\end{abstract}

Palavras-chave: Empreendedorismo Feminino. Capital Social. Participação. Autogestão.

\footnotetext{
* Professora do Departamento de Comunicação e Turismo da UFPB. Doutoranda do PRODEMA/UFPB/ Brasil. E-mail: patriciamoraisrp@gmail.com

** Professora Titular aposentada do Departamento de Ciências Sociais da UFPB. Doutorado em Sociologia pela Université Sorbonne Nouvelle - Paris 3/França. E-mail: andrademaristela@hotmail.com
} 


\begin{abstract}
This article aims to discuss the role of women artisans in the context of female entrepreneurship, considering that they are increasingly positioning themselves in the labor market with the opening of their own business, either individually or collectively, as it happens with the associations and cooperatives of artisans, farmers, among others. It seeks to understand female entrepreneurship from the perspective of the concepts of social capital, participation and self-management, based on the experience of the work developed by women artisans who are part of the Mãos que se Ajudam Association in the municipality of Lucena / PB. The methodology of the research was based on bibliographical research and participant observation, as well as on semi-structured interviews and application of questionnaires to members of the Association (president, cocada (coconut sweet) makers, coconut fiber artisans). Also interviewed were public managers who participate directly in the constitutive process of this Association. Finally, it was verified that the female entrepreneurship researched revealed the participation and accumulation of social capital of artisans in the productive sphere of cocada (coconut sweet), but in the sphere of self-management, the results were unsatisfactory. Women's low level of education, just as their previous experience in the world of work being limited to domestic activities would be factors that made it difficult for them to comprehend their role as entrepreneurs. The inclusion of women in the association in search of a source of income favored an identification with wage labor, thus far from achieving the objectives of self-management.
\end{abstract}

Key world: Female Entrepreneurship. Self management. Social capital. Participation.

\title{
Introdução
}

Atualmente, no Brasil, são 12 milhões de pessoas desempregadas (PNAD, 2017), sendo que 49,30\% são homens e 50,70\% são mulheres. Por isso, alcançar um lugar no mercado de trabalho é desejo de todos, sendo, de forma geral, a busca pelo melhor emprego, pelos melhores cargos e/ou pelas melhores profissões no mercado de trabalho, o que, por sua vez, aumenta a competitividade a cada dia. Por outro lado, o avanço da tecnologia tem sido responsável pela eliminação definitiva de postos de trabalho nas mais diversas áreas, isto porque a automação de processos produtivos provocou uma diminuição na demanda de mão de obra humana, abriu vagas para pessoas especializadas e com maior grau de instrução, e aumentou o número de pessoas desempregadas em todo o país (FECOMÉRCIO, 2017).

Com isso, a falta de oportunidade e de reposicionamento no mercado de trabalho, a falta de qualificação para as vagas existentes em áreas específicas e a necessidade de sobrevivência fazem com que muitos indivíduos, atentos ao mercado e suas demandas, arrisquem suas economias na abertura do próprio negócio, ou seja, alimentando o segmento de empreendedorismo por necessidade e/ou oportunidade (BEDÊ, 2015).

As mudanças ocorridas na estrutura e no processo de produção e de relações trabalhistas sempre existiram. Ao longo do tempo, promoveram grandes impactos na organização dos grupos sociais, assim como na sociedade em seu todo. Com a Revolução Industrial e sua nova forma de produção, o uso das máquinas, a produção em série, a implantação de normas trabalhistas, a contratação da mão de obra de 
mulheres e crianças, entre outros fatores, atingiram diretamente a organização de diversos grupos sociais, promovendo um grande impacto e uma desagregação social que estimulou a necessidade de se buscarem novas formas de organização empresarial (POLANYI, 2000).

Para Gaiger (2011), as mudanças que ocorreram ao longo dos anos, no cenário empresarial e social, oriundas do processo de reestruturação produtiva e, também, as transformações na estrutura econômica e nas relações de trabalho ocorridas no final do século XX, geraram uma mão de obra excedente e de difícil absorção no mercado de trabalho. Este cenário acabou por instigar a busca de novas formas de produção, daí o aumento do trabalho informal, assim como de pequenos negócios e empresas familiares.

A mulher, durante esse processo, foi conquistando seu lugar no mercado, porém, ela também é atingida por diversos fatores que interferem tanto na sua vida profissional como na vida pessoal, tais como desigualdade salarial, ocupação de cargos inferiores, dupla jornada de trabalho etc. O contexto no qual ela está inserida cobra-lhe a responsabilidade de cuidar da família e da realização profissional; consequentemente, a mulher busca, trabalhar para si e começa, muitas vezes de forma autônoma, prestando serviço na área em que está mais habilitada ou, até mesmo, abrindo seu próprio negócio de forma legalizada, ou seja, registrando sua empresa e pagando os impostos devidos.

Dentre as atividades mais exercidas pelas mulheres, estão aquelas relacionadas ao seu cotidiano como dona de casa; assim, muitas prestam serviço como diaristas, babás, cuidadoras de idosos e artesãs (COSTA, 2012). Aquelas que possuem qualificação profissional de formação abrem outros tipos de negócio, de acordo com sua habilidade e seu conhecimento sobre o mesmo. Os segmentos de beleza e alimentação são os tipos de negócio que recebem mais investimento pelas mulheres (BEDÊ, 2015), devido a sua afinidade com essas áreas, assim como pela possibilidade de desenvolverem negócio em suas residências ou nas proximidades delas, favorecendo a convivência e o cuidado com a família e, principalmente, com os filhos.

É neste viés do empreendedorismo que será investigado como as mulheres artesãs conduzem seu negócio, sob a perspectiva do capital social e da autogestão. Esta é compreendida como a capacidade de gerir seu próprio negócio com inovação e visão de mercado; capital social consiste na junção do conhecimento individual em prol de um objetivo coletivo, comum a todos que formam uma organização/ associação e têm nela participação, ou seja, envolvimento em todo o processo de gestão do negócio (GUTIERREZ, 1988).

Será tomada por base a experiência de um grupo de mulheres que formaram, em 2003, a Associação Mãos que se Ajudam, no Município de Lucena/PB - AMQSA, com o objetivo de criar uma oportunidade de trabalho em torno de um produto do conhecimento comum e com uso de uma matéria-prima local, o coco, para produzir cocada. A fibra do coco, por sua vez, é usada para produzir o artesanato e as bijuterias e, assim, gerar renda para essas artesãs e suas famílias.

$\mathrm{O}$ interesse em desenvolver uma pesquisa com base na experiência da Associação dessas artesãs paraibanas surgiu a partir do acompanhamento dessa 
Associação por uma das autoras, graças a sua atuação junto ao Serviço de Apoio às micro e pequenas empresas - SEBRAE/PB, no período entre 2008 e 2009, quando trabalhou na aludida instituição como Relações Públicas. Nesse período, a ex-presidente e fundadora da Associação foi a vencedora do Prêmio Mulher de Negócios, tanto no âmbito estadual como no nacional, concedido pelo SEBRAE Paraíba e pelo SEBRAE Nacional, respectivamente.

Com isto, busca-se avaliar até que ponto as políticas de incentivo ao empreendedorismo levam em conta o despreparo das mulheres para autogestão?

\section{Procedimentos metodológicos}

Para a composição do referencial teórico deste artigo se fez uso da pesquisa bibliográfica, por meio de consulta a livros, artigos, periódicos, anais, teses sobre os temas convergentes nesta pesquisa, tais como empreendedorismo feminino, autogestão, mulheres artesãs, entre outros, embasados em autores como Bourdieu (1980), Bordenave (1994), Dornelas (2007), Polanyi (2000), Gaiger (2011), Gomes et al. (2011) etc.

Para o levantamento dos dados, na pesquisa de campo, foram utilizadas as seguintes técnicas: observação sistemática direta, quando o pesquisador se vale dos sentidos (ver e ouvir) para a obtenção dos dados em determinado período de tempo, sistematizando-os durante a produção do diário de campo, com anotações e fotografias do ambiente; e observação participante, para a qual foi escolhido o espaço da cozinha, onde a proximidade com as mulheres foi muito maior e, assim, buscouse vivenciar as conversas informais e as fofocas do dia a dia das mulheres durante a preparação das cocadas etc. A coleta de dados se deu durante as visitas à Associação Mãos que se Ajudam, no período de março a setembro de 2016, uma ou duas vezes por semana, ao longo de seis (6) horas, seguindo os dias de produção na referida entidade.

A entrevista semiestruturada foi outra técnica utilizada a fim de promover a maior contribuição por parte dos entrevistados, buscando-se sempre o foco da pesquisa (LAKATOS, 2007). Esta foi mais utilizada junto aos gestores públicos de órgãos como SEBRAE ${ }^{2}$ - 01 entrevistado -, Projeto COOPERAR/PB ${ }^{3}$ - 01 entrevistado e, também, dois membros da Associação: sua presidente e sua tesoureira/cocadeira.

Por fim, vale ressaltar a observação participante realizada na cozinha do estabelecimento, através da permissão obtida pela pesquisadora de acompanhar o

\footnotetext{
1 Este artigo é parte da tese de doutorado intitulada: "O empoderamento das mulheres na agenda do desenvolvimento territorial sustentável, no município de Lucena/PB”, em vias de produção no Programa de Pós-Graduação em Desenvolvimento e Meio Ambiente - PRODEMA/UFPB.

2 O SEBRAE/PB contribui capacitando as mulheres sobre a autogestão do negócio.

3 Projeto COOPERAR-PB é uma agencia governamental da Paraíba para inclusão social que recebe recursos do Banco Mundial para seus projetos.
} 
processo produtivo da Cocada na Quenga, momento em que as conversas informais acrescentaram informações importantes ao trabalho de pesquisa. Elas permitiram ganhar a confiança das mulheres, aprender e trocar experiências pessoais, além de ouvi-las de forma mais espontânea sobre seu trabalho, mesmo cientes do interesse da pesquisadora quanto ao tema do empreendedorismo feminino.

O mesmo procedimento ocorreu com as mulheres do artesanato. Nesse sentido é importante relembrar que a AMQSA tem como carro-chefe a Cocada na Quenga ${ }^{4}$, mas também existe o artesanato da fibra de coco, com a produção de bijuterias, peças de ornamentação e utensílios de cozinha. A pesquisa foi realizada com os dois grupos de mulheres artesãs que integram a referida Associação, e os resultados apresentados envolvem as duas partes.

\section{Capital social e participação para autogestão das mulheres empreendedoras}

Um conceito que está diretamente relacionado ao de empreendedorismo e que fortalece o empoderamento das mulheres é o de capital. Para a sociologia, mais especificamente para Marx, capital é sinônimo de produto da mais-valia que o trabalhador produz e que fica sob o poder dos donos da produção (POLANYI, 2000). Porém, há vários tipos de capital reconhecidos e identificados na sociedade, dentre eles, o capital humano, que se encontra nas habilidades e competências desenvolvidas pelo indivíduo; o capital econômico, relacionado aos valores monetários e aquele para o qual tudo converge; e o capital social, que requer a relação entre as pessoas, em busca de benefícios em comum, tais como informações sobre negócios, empréstimos, o aumento da rede de relacionamento etc. (PORTES, 2000), com compartilhamento social de seus valores, resultados econômicos e a promoção do crescimento mútuo. Pierre Bourdieu define capital social como:

O capital social é o conjunto de recursos atuais ou potenciais que estão ligados à posse de uma rede durável de relações mais ou menos institucionalizadas de interconhecimento e de inter-reconhecimento ou, em outros termos, à vinculação a um grupo, como conjunto de agentes que não somente são dotados de propriedades comuns (passíveis de serem percebidas pelo observador, pelos outros ou por eles mesmos), mas também são unidos por ligações permanentes e úteis (BOURDIEU, 1980, p.1).

Esta definição de capital social destaca a formação de uma rede de relacionamento, com interesse comum, que gera solidariedade e promove benefícios a todos aqueles que visam interagir com confiança e obter resultados econômicos, aumentar seu capital cultural e formar instituições que possuam credenciais valorizadas.

4 A Cocada na Quenga tornou-se um doce típico do Município, a partir da produção realizada pela Associação Mãos que se Ajudam. 
De acordo com Portes (2000), estudos apontam que, além dos benefícios, o capital social também proporciona algumas consequências e estas estão pautadas em três funções básicas. A primeira diz respeito ao controle social a partir da criação de regras que objetivam manter a ordem social para o bem comum; a segunda diz respeito ao capital social como fonte de apoio paternal e familiar, partindo do princípio de que uma família na qual o cônjuge está presente na formação da criança, favorece a construção de sua personalidade, caráter e, também, no seu desempenho na sociedade enquanto elemento formador e participante de diversas redes de relacionamento. A terceira função do capital social indica como este pode ser fonte de benefícios através de redes extrafamiliares.

Esta terceira função relacionada ao capital social não se mostra condizente com os propósitos de fundação de uma associação, conforme será analisado neste trabalho, pois, além da rede de relacionamento externa, muitas mulheres necessitam do apoio familiar para acreditar em seu trabalho e para desenvolvê-lo. $\mathrm{O}$ apoio, o incentivo, a compreensão e o bom convívio familiar são elementos fundamentais para que mulheres artesãs e demais artesãos tornem-se aptos a conduzir seus negócios.

O capital social possui, também, algumas consequências negativas nos seguintes aspectos (BOURDIEU, 1980): 1) impedir a entrada de pessoas que não fazem parte do grupo, 2) exigir dedicação excessiva a membros do grupo, geralmente por terem certa proximidade familiar, dando acesso fácil a cargos e/ou benefícios e prejudicando o crescimento do negócio; 3) restringir a liberdade individual - a sociedade na qual o indivíduo está inserido mantém um controle social forte, a ponto de muitos jovens deixarem a mesma devido à falta de liberdade; e 4) estabelecer normas de nivelação descendente, ou seja, quando alguém almeja participar de um grupo o qual não é o seu de origem, perpassa normas, valores e promove, até mesmo, transformações físicas para ser aceito em outro grupo, sendo, dessa forma, estigmatizado e criticado pelos seus pares.

Apesar de essa abordagem ser relevante, afinal, em tudo há pontos positivos e negativos, busca-se entender como o capital social está inserido no contexto de Associação de mulheres artesãs, tendo em vista que as associações trabalham em prol da melhoria de capacitação profissional, dos interesses comuns e na defesa dos direitos dos associados (DALMORO, 2009).

Outra característica fundamental para os empreendedores e seus negócios é a participação. De acordo com Hellwig e Carrion (2007), o homem, desde sua existência, possui a participação como uma de suas características fundamentais para viver em sociedade. Daí ser importante saber avaliar tanto o grau de participação individual como o envolvimento pessoal no processo decisório dos membros de uma organização.

Para Bordenave (1994), há vários graus de participação e de envolvimento do indivíduo, e que interfere diretamente nas decisões a serem tomadas. $\mathrm{O}$ primeiro deles é a informação - quando os dirigentes informam apenas as decisões tomadas e estas podem gerar reação ao ponto de serem reformuladas. $\mathrm{O}$ segundo diz respeito à consulta facultativa - consultas esporádicas sobre a opinião dos trabalhadores para a resolução de problemas. A consulta obrigatória é o terceiro grau de participação. 
Ela consiste em uma consulta formal aos trabalhadores sobre algo predeterminado. O quarto grau de participação é a elaboração/recomendação realizada pelos trabalhadores aos dirigentes, sendo que estes podem ou não acatar as sugestões dadas. A cogestão é o grau que consiste numa administração compartilhada, na qual os trabalhadores, por meio de colegiados, participam das decisões. O sexto grau é a delegação, ou seja, são limites dados para a tomada de decisões, em determinadas áreas. A autogestão é o grau mais alto de participação, segundo o autor. Por meio dela, o grupo toma suas decisões, escolhe os meios, as formas de controle e seus objetivos. É a que mais se adequa, também, ao contexto das Associações formadas a partir da Economia Solidária.

A partir do momento em que há uma vontade coletiva para produzir algo que proporcione o bem comum, de acordo com a vontade e a decisão de todos, uma empresa passa a ser gerida pelo coletivo e a isto se denomina autogestão. Cada um busca contribuir de acordo com seu conhecimento, sua experiência, porém de forma que haja um incentivo à produção e ao crescimento do negócio (GUTIERREZ, 1988).

\section{Empreendedorismo e sua interface com o mercado de trabalho}

O conceito de empreendedorismo é abordado sob diversos aspectos, sendo os principais, para a maioria dos autores, definidos como as formas de gestão de micro e pequenas empresas, e o perfil do empreendedor. $\mathrm{O}$ ato de empreender representa muito mais do que criar um produto, uma empresa ou um processo. Ele significa o compartilhamento de ideias, conhecimentos e experiências. De forma geral, o empreendedorismo promove a criação de soluções para problemas no âmbito pessoal, social, por meio de inovação e com viés econômico e social. Como diz Dolabela,

Empreender é um processo humano, com toda a carga que isso representa: ações dominadas por emoção, desejos, sonhos, valores, ousadia de enfrentar as incertezas e de construir a partir da ambigüidade e no indefinido; consciência da inevitabilidade do erro em caminhos não percorridos; rebeldia e inconformismo; crença na capacidade de mudar o mundo; indignação diante de iniqüidades sociais. Empreender é, principalmente, um processo de construção do futuro (DOLABELA, 2003, p. 29).

O empreendedor, por sua vez, possui características específicas que o ajudam a desenvolver as habilidades necessárias em seu negócio, tais como: poder de decisão, capacidade de assumir riscos, autoconfiança, responsabilidade, próatividade, entre outras. Porém, não basta apenas ter um espírito empreendedor para abrir um negócio. É necessário, também, saber inovar, criar formas de organização, desenvolver produtos e serviços que possam gerar e atender a demandas na sociedade, ou seja, manter um nicho de mercado com potencial de crescimento, desenvolvimento e permanente inovação (DOLABELA, 2003).

De acordo com Schumpeter (1982), existem etapas que devem ser estabelecidas e cumpridas para que o empreendedor possa se estabelecer no 
mercado e contribuir para o desenvolvimento econômico. A primeira etapa consiste em colocar um novo produto no mercado para suprir alguma necessidade do consumidor, ou melhorar um produto já existente por meio da inovação. A segunda requer inovação no processo produtivo. A terceira diz respeito à abertura de um novo mercado, de preferência que ainda não tenha sido explorado e para que haja pouco ou nenhum concorrente. A quarta etapa trata de um fornecedor de matériaprima diferenciado, também, inovador. E, por fim, a quinta etapa diz respeito à estruturação de uma nova forma de organização.

Diante das etapas do empreendedorismo elencadas por Schumpeter (1982) e das características do empreendedor apontadas anteriormente, verificou-se que, de acordo com a mudança dos mercados, há, também, uma mudança contínua e diversificada nas formas de empreender, proporcionando ao empreendedor uma segmentação de áreas de atuação.

Para Dornelas (2007), há oito tipos de empreendedores, dentre os quais dois se destacam para compreender o empreendimento feminino pesquisado. $\mathrm{O}$ autor os classifica da seguinte maneira: o empreendedor por necessidade - aquele que, após ser demitido ou por estar fora do mercado há algum tempo, só tem como alternativa abrir seu próprio negócio e, muitas vezes, de maneira informal; e o empreendedor social - aquele que elabora projetos a fim de criar oportunidades de trabalho e renda para outras pessoas, não visa lucro financeiro para si, e sim o desenvolvimento de pessoas.

A partir da leitura de Dornelas (2007), entende-se que é por meio do último tipo de empreendedor mencionado acima que o Empreendedorismo Social está ocupando seu lugar no campo de trabalho, já que favorece e beneficia muitos indivíduos que possuem habilidade, competência, mas que estão fora do mercado. Com isso, há abertura de novos mercados, estímulo à produção e desenvolvimento econômico e social visando à sustentabilidade.

\section{Empreendedorismo feminino na interface entre gênero e trabalho}

O conceito de gênero aqui abordado refere-se, especificamente, às relações sociais no âmbito do trabalho, que propõe que deve haver um equilíbrio na relação entre homem e mulher, e que, para que haja equidade entre ambos, é necessário que sejam criadas oportunidades para todos. Entretanto, não é isso o que acontece na sociedade, daí a importância de pesquisas para que se busque o entendimento sobre o papel, os direitos e deveres da mulher na sociedade, assim como seu desenvolvimento profissional.

Gênero não é sinônimo de mulheres, nem tampouco configura situação em que o ganho de um determina perda para o outro, no caso, homens. Pelo contrário, refere-se a ambos, mulheres e homens, e a seu status em relação a cada um deles. Equidade de gênero se refere ao estágio de desenvolvimento humano no qual 'direitos, responsabilidades e oportunidades de indivíduos não serão determinados pelo fato de terem nascido homem ou mulher' (ZAHIDI, 2005, p. 4). 
A autonomia econômica da mulher é um dos principais temas do movimento feminista, devendo ser analisados vários aspectos a esse respeito, tais como: a geração do trabalho e renda, a erradicação da pobreza, a economia solidária, o desenvolvimento econômico e social e a assistência social (COSTA, 2012). Avaliar seu acesso ao mercado de trabalho, principalmente o da mulher das classes mais populares, é uma constante nos debates que, também, discutem como a divisão sexual do trabalho interfere nesta autonomia.

De acordo com Gomes et al. (2011), existem quatro motivos pelos quais as mulheres buscam o empreendedorismo: o primeiro é a realização pessoal: ser dona de seu próprio negócio é a realização de um sonho; o segundo diz respeito a uma oportunidade de mercado; o terceiro motivo está relacionado ao cenário machista e excludente que há nas empresas: trata-se da dificuldade de ascensão na carreira profissional; o quarto motivo é a necessidade de sobrevivência diante da falta de oportunidade no mercado de trabalho, juntamente com a possibilidade de cuidar mais de perto da família e dos filhos. Na maioria das vezes, as oportunidades são seletivas, pois os homens são vistos como os mais qualificados e preparados para assumir determinadas vagas no mercado de trabalho, permanecendo, assim, a divisão sexual do trabalho e, consequentemente, a desigualdade salarial. Por outro lado, tendo em vista que muitas mulheres não possuem outra profissão, muitas delas iniciam seus negócios ainda dentro de casa ou buscam algo com que tenham mais afinidade para trabalhar.

Uma das áreas de atuação da mulher empreendedora é o artesanato, por ser essa uma atividade de habilidade manual associada ao trabalho feminino. $\mathrm{O}$ artesanato proporciona uma forma de produção que pode ou não gerar bens econômicos; entretanto, sua maior vantagem encontra-se na geração de trabalho para grupos de mulheres que almejam ocupar um lugar na sociedade.

A relação do trabalho feminino com o artesanato existe desde o início da Revolução Industrial (GAIGER, 2011). Naquele período, se fazia necessário o emprego de mulheres para conduzir a produção, principalmente a têxtil, que requeria habilidades e cuidados, os quais as mulheres eram mais qualificadas a desenvolver. Com a evolução da tecnologia, os trabalhos artesanais passaram a ser substituídos pelas máquinas, e isto afetou diretamente no posicionamento das mulheres no mercado, pois as mesmas, além de não possuírem capacitação adequada, eram vistas como mão de obra para trabalhos delicados, tais como o artesanato e as atividades domésticas.

A partir da criação de setores públicos focados no desenvolvimento e empoderamento das mulheres, tais como a Secretaria Especial de Políticas Públicas para Mulheres (COSTA, 2012), as oportunidades criadas para a geração de emprego e renda, o fomento à criação e gestão de novos empreendimentos econômicos, percebe-se que há um estímulo para que a mulher participe de forma mais ativa no processo econômico, assim como tenha mais autonomia e liberdade financeira, contribuindo, também, para a igualdade de gênero na sociedade. De acordo com a pesquisa divulgada pelo Global Entrepreneurship Monitor - GEM (2017), no Brasil, há um equilíbrio entre gêneros na constituição de novos estabelecimentos, sendo 19,9\% para mulheres e $19,2 \%$ para os homens. 
O empreendedorismo feminino da Associação Mãos que se Ajudam de Lucena/ Paraíba

Para chegar à AMQSA, faz-se um deslocamento, por balsa, do Município de Cabedelo para o Município de Lucena, situado no litoral Norte da Paraíba, a $52 \mathrm{~km}$ da capital. O Município possui uma população estimada de 13.121 habitantes, seu Índice de Desenvolvimento Humano Municipal - IDHM é de 0,583 (IBGE, 2017); a cidade possui vocação turística e turismo de segunda residência durante os meses de verão, além de ter, também, a pesca e a agricultura como atividade produtiva.

A AMQSA tem como base produtiva a Cocada na Quenga, além da produção de bijuterias e objetos a partir da fibra do coco, produtos artesanais criados pelas mulheres artesãs, para promover emprego e renda na comunidade. Ela surgiu em 2003, a partir da visão de duas mulheres recém-chegadas do interior de São Paulo, com experiência no mercado de trabalho nas áreas de psicologia e advocacia em grandes indústrias, com formação superior e um olhar diferenciado sobre o papel da mulher na sociedade e, consequentemente, sobre o cenário local do Município de Lucena.

As idealizadoras do projeto da AMQSA achavam que as mulheres da comunidade estavam "ociosas" e ouviram de algumas delas, segundo a atual presidente e fundadora da Associação, a necessidade de se sentirem produtivas, pois, em sua maioria, eram donas de casa e mulheres de pescadores, e dependiam financeiramente dos maridos para tudo.

O trabalho no campo teve início em maio de 2014, quando ocorreram as primeiras visitas (no total foram doze visitas) à Associação, para a apresentação do projeto de pesquisa aprovado no curso de doutorado no Programa de Desenvolvimento e Meio Ambiente (PRODEMA) da Universidade Federal da Paraíba.

Em uma segunda visita, no mesmo período, teve-se conhecimento das instalações da Associação e houve apresentação da pesquisadora para as mulheres que estavam na produção da cocada e no artesanato, com informações sobre o objetivo da visita e o trabalho que seria realizado naquela Instituição. A visita foi guiada pela Presidente da Associação, que recepcionou a pesquisadora de forma muito prestativa. $\mathrm{Na}$ ocasião foram obtidas as primeiras informações sobre o histórico do surgimento da Associação, numa conversa que durou uma hora e oito minutos e na qual vários temas foram abordados de forma sucinta, tais como: gestão, capacitação, projetos para financiamento, relacionamento interno, relacionamento com clientes e fornecedores, melhoria na vida das mulheres com participação na Associação. Inicialmente buscou-se entender como ela surgiu, conforme se vê no seguinte trecho:

LE- A Associação? A ex-presidente chegou primeiro na Paraíba. Enquanto ela estava... Eu cheguei praticamente uns seis meses depois. Quando ela estava aqui, ela começou a sentir a mesma coisa que eu senti quando eu cheguei: que as mulheres não tinham o que fazer. Estavam todas sentadas na rua e conversa e aquilo lá sem ter o que fazer. Aí ela tava procurando questões. Daí eu cheguei. 
Nós já nos conhecíamos lá de São José dos Campos... (Entrevista com a presidente da Associação, realizada dia 05 de maio de 2014).

Analisando a partir dos tipos de empreendedores elencados por Dornelas (2007), e já apresentados anteriormente, as idealizadoras da AMQSA podem ser consideradas empreendedoras sociais, ou seja, pessoas que buscaram criar uma entidade que proporcionasse a geração de emprego e renda para as mulheres da comunidade de Lucena.

Entretanto, com base nas informações iniciais levantadas durante a pesquisa, foi percebido que não houve, de forma clara, um interesse por parte das mulheres da comunidade em formar esta Associação. A principal preocupação delas era conseguir um trabalho e aumentar sua renda para ajudar a família, ou seja, elas foram identificadas como empreendedoras por necessidade, por buscarem um posicionamento no mercado de trabalho.

De acordo com a presidente, as mulheres que participaram da formação da AMQSA moravam em vários bairros de Lucena e foram informadas umas pelas outras sobre o projeto, ou seja, houve um uso das redes de conhecimento coletivo para a elaboração de um produto que pudesse atender aos interesses de todos, assim como a formação de um grupo com reconhecimento de relações na comunidade, ou seja, as mulheres chamavam pessoas conhecidas, com certo grau de afinidade para compor a Associação. Elas somaram, além do conhecimento culinário, várias experiências de vida, de cultura, em prol de um objetivo em comum: criar um lugar onde pudessem exercitar sua cidadania, gerar renda e desenvolvimento mútuo, ou seja, estas características estão relacionadas ao que foi definido por Bourdieu (1980) como uso do capital social.

Atualmente dez mulheres trabalham na produção da Cocada na Quenga e quatro, no artesanato. A faixa etária delas está entre 29 e 56 anos. A maioria possui ensino fundamental ou ensino médio incompleto, apenas três integrantes completaram o ensino fundamental e apenas uma concluiu o ensino médio. Há uma integrante que não possui escolaridade, porém, sabe assinar seu nome. A maioria entrou na Associação por indicação durante os anos de desenvolvimento do trabalho; poucas (duas ou três) estão desde a formação da Associação, que, no início, contava com vinte e duas mulheres, de modo que aquelas que deixaram de contribuir saíram por terem conseguido emprego com carteira assinada ou mudado de cidade ou estado, segundo as que permanecem. Com isso, a Associação perdeu praticamente a metade de suas associadas. ${ }^{5}$

Pressupõe-se, assim, que a formação da AMQSA partiu de um processo de construção do capital social, quando as mulheres buscaram, também, orientação no SEBRAE, para organizar o processo de gestão e aperfeiçoar seus conhecimentos

5 Além das mulheres, há dois homens associados: um motorista e o cortador de coco. O motorista conduz o carro para eventos e faz a entrega de cocadas nos pontos de revenda, e o cortador de coco, além do trabalho braçal de cortar o coco, também, compra coco quando necessário. 
técnicos por meio de capacitação. Isso as levou ao crescimento não apenas pessoal, mas coletivo, a partir do momento em que passaram a ter visibilidade, qualificaram melhor seu produto e melhoraram as condições de trabalho para aumentar a produção.

Outro ponto positivo sobre o uso do capital social é o estabelecimento da confiança entre as mulheres, seus parceiros, seus clientes, o que auxilia o fortalecimento da Associação e contribui para seu desenvolvimento e posicionamento no mercado, com a produção de um produto que tem por base o conhecimento coletivo e a representação social de um local.

Em outro relato da presidente, encontrou-se um argumento utilizado para incentivar as mulheres a começar o trabalho e enfrentar as adversidades que surgiram, tendo em vista que todas elas sofreram forte discriminação tanto pelo novo posicionamento frente à sociedade, como pelo nome adotado para o produto que seria comercializado - a "cocada na quenga" -, devido ao fato de o termo "quenga"6 ter duplo sentido. O depoimento abaixo revela os preconceitos iniciais dos maridos e da sociedade:

HO - No início... preconceito... eu acho que nem tanto... o preconceito que aparecia antes, antes nome cocada na quenga, aí a gente sempre passava e escutava assim, piadinha: oh, lá vai as quengas; oh, cocada da quenga, não é cocada na quenga. Esse tipo de piadinha que no início a gente escutava, mas levava na esportiva. Até os turistas quando chegava, para aí: eita que aqui tá cheio de quenga, tem quenga de toda qualidade (Entrevista com Cocadeira/ Tesoureira, realizada dia 10 de agosto de 2016).

A força de vontade de buscar uma ocupação trouxe às mulheres da Associação, num primeiro momento, muita discriminação, a começar pelos maridos, que não aprovavam a saída das mulheres para o mercado de trabalho e criavam muitos empecilhos, desde a recusa ao auxílio nas atividades domésticas até a negação de refeição às mulheres durante o expediente de trabalho. Na fala anterior, a entrevistada deixa claro que havia um preconceito, porém, a mesma não o reconhece como tal. Percebe-se que é uma sociedade preconceituosa e machista que não incentiva o desenvolvimento do trabalho realizado pelas mulheres artesãs.

Sabe-se que persistência e determinação são características fortes para os empreendedores. Após catorze anos de fundação da Associação, a persistência dessas mulheres fez com que o negócio prosperasse, assim como seu posicionamento na relação familiar e na sociedade na qual estão inseridas. Elas trabalharam muito para tal reconhecimento, conforme fala a tesoureira:

A gente trabalhou muito. Você acredita que teve uma vez, Patrícia, a gente amanheceu o dia fazendo cocada. Ninguém dormiu, a gente entrou era oito da noite porque tinha uma encomenda e era assim se tivesse encomenda a gente

6 Dicionário Aurélio online: [Brasil: Nordeste] Vasilha feita com a metade de um coco. [Chulismo] Prostituta. Disponível em https://www.dicio.com.br/aurelio-2/ . 
tinha que vir a qualquer hora. Se tivesse, sábado, domingo, segunda, feriado, a gente vinha (Entrevista com Cocadeira/Tesoureira, realizada dia 10 de agosto de 2016).

Além disso, leva-se em consideração o fato de "assumir riscos" ser uma característica muito forte e presente durante o processo de desenvolvimento dessa Associação. Passaram a fornecer um produto simples e de fácil acesso a todos, com base em um conhecimento local aprimorado, para se posicionarem no mercado, com inovação tanto em sua forma de produção como em sua embalagem. Outro risco que aceitaram correr foi a participação em concorrência para financiamento de projetos em diversos órgãos, como a Fundação Banco do Brasil e o Cooperar.

Segundo relato da atual presidente da Associação, ratificado em entrevista à tesoureira, a maioria das mulheres aumentou o poder aquisitivo de suas famílias, mobiliou a casa, voltou a estudar, ofereceu melhor condição de estudos para seus filhos e, principalmente, conquistou o respeito e o apoio dos maridos, que hoje tanto as auxiliam nas atividades domésticas, como levam a refeição para as mesmas, durante o dia de trabalho.

Estes dados levantados em entrevistas e durante as conversas informais com as cocadeiras, demonstram que houve um período em que o volume de trabalho favorecia a melhoria da condição de vida delas, pois obtinham uma renda que era mais satisfatória do que atualmente. Foram poucas as mulheres da Cocada na Quenga e do artesanato que, realmente, conseguiram uma evolução significativa equipando suas casas, melhorando as condições de estudo dos filhos, embora esta avaliação seja prejudicada pela permanência de apenas três mulheres do grupo inicial. Diante do atual cenário econômico de crise, retração do mercado, diminuição dos pedidos, do fluxo turístico etc., todas reclamam da baixa remuneração, pois doze dos dezesseis pesquisados têm nessa atividade a única fonte de renda da família e apenas quatro afirmam ter outra atividade com remuneração.

A Associação, após seu registro enquanto pessoa jurídica, participou de diversas concorrências junto aos órgãos estaduais, como o Cooperar e algumas empresas, a exemplo da Fundação Banco do Brasil, a fim de obter recursos financeiros e materiais que viabilizassem o melhor funcionamento da Instituição. Os projetos destinados a concorrer a um financiamento eram elaborados sempre pelas lideranças, ou seja, pela presidente e/ou sua vice, conforme foi relatado pela atual gestora.

Percebe-se que o início da Associação foi fruto de uma ação externa apoiada pelo Governo do Estado e agências estaduais de fomento ao desenvolvimento, e não de um desejo das mulheres locais, embora as mesmas tenham se posicionado ao opinarem sobre o tipo de atividade que se consideravam aptas a desenvolver; uma parte delas optou pela cocada e outro grupo, por confeccionar produtos de limpeza, daí a Associação ter os dois segmentos em sua razão social. O trabalho do grupo começou com uma conscientização de mulheres locais para desenvolver um trabalho com base no conhecimento tradicional e naquilo que viesse a ser referência no Município. 
Quanto à forma de gestão da AMQSA, sempre foi centralizada e conduzida pela presidente e vice-presidente, num processo de gestão verticalizado, em que as decisões foram tomadas de cima para baixo. Isso fica claro no organograma repassado verbalmente pela atual presidente: presidente, vice-presidente (membros externos), secretária/tesoureira, cocadeira/cortador de coco/motorista, artesãs do resíduo do coco (demais membros nativos).

Com isso, a autogestão ainda está distante de ser efetivada e sua ausência compromete o desenvolvimento do negócio, tendo em vista que as mulheres da Associação se comportam como funcionárias e não apresentam uma pró-atividade para gerir o negócio. Foi observado, durante o convívio com estas mulheres, que todas as decisões da Associação partem da presidente e da vice-presidente. As mulheres artesãs estão focadas apenas na produção, pelo fato de todas elas terem como objetivo a necessidade de obter renda no final do mês. Além disso, a cultura de valorização do emprego é muito presente, e as associadas esperam que alguém tome decisões e as repasse para elas. Isso se evidencia quando a tesoureira afirma: "Nossa! o salário mínimo tava ótimo. Se fosse mais melhor, mas o salário fixo todo mês, acho que todo mundo trabalhava aqui feliz da vida. Um salário. Não bastava mais que um salário."

$\mathrm{Na}$ atual gestão, percebe-se que a presidente almeja tornar as mulheres mais comprometidas com o processo burocrático e lhes delegar algumas responsabilidades, assim como informar-lhes sobre os trâmites burocráticos em vigência. As mulheres, porém, demonstram muita dificuldade no entendimento desses processos burocráticos e financeiros, assim como não compreendem as exigências da vigilância sanitária dos exames periódicos a qual requer atestados de saúde delas para liberar o manuseio e a produção de alimentos. Do ponto de vista da presidente, o processo de gestão da Associação está restrito apenas às decisões tomadas durante as Assembleias, conforme diz a presidente quando questionada sobre como é o processo de gestão: “o processo de gestão é através de assembleia. Então se apresentam chapas e a própria assembleia vota em quem eles quiserem.”

Em contrapartida, quando a gestora do Programa Cooperar foi entrevistada, um dos pontos que ela ressaltou foi a falta de capacidade das mulheres para gerir o negócio, o que é exemplificado pela preocupação com a continuidade do negócio:

Quando nós chegamos lá pra fazer um trabalho, uma avaliação, da análise física e financeira do projeto e ver a viabilidade deles se tava dando lucro ou prejuízo, a gente viu que elas não conheciam nada. A maior dificuldade até pra gente levantar o patrimônio, elas não sabiam de nada, não tinham acesso à parte de informática, não tinham acesso a uma impressora, a tirar uma xerox, "e esse ventilador foi de qual programa?" "eu não sei", não sabia de quem era o ventilador, não sabia de que recursos foi, os equipamentos também, aqueles equipamentos também pra própria fabricação da cocada. Tudo isso eles não sabiam de nada. Essa foi a dificuldade que nós tivemos. Levantamos o patrimônio e depois fomos para o custo de produção da cocada. Levantamos o passo a passo com elas (Entrevista realizada com gestora do Cooperar/PB, realizada no dia 11 de julho de 2016). 
Apesar da falta de envolvimento direto nos processos de gestão, as mulheres artesãs até buscam a participação, mas, devido à forma de gestão implantada desde a fundação, ela se tornou limitada. Analisando as formas de participação elencadas por Bordenave (1994), pode-se dizer que as mulheres da AMQSA têm sua atuação restrita ao nível de informação das decisões, não sendo consultadas na tomada de decisão; apenas absorvem as informações repassadas pela diretoria. Pouco exprimem sua opinião ou interferem nas decisões tomadas, apesar de a Associação ter um formato de colegiado no qual decisões devem ser tomadas em assembleia, com a participação de todos.

\section{Considerações finais}

O propósito deste trabalho foi verificar como as mulheres artesãs da AMQSA, no Município de Lucena, conduzem seu negócio sob a perspectiva do capital social e da autogestão. Com os resultados parciais da pesquisa, verificou-se que essas mulheres, por terem um baixo grau de instrução e não terem recebido capacitação para a gestão financeira e o negócio, apresentaram dificuldade no processo de autogestão da Associação.

De acordo com os dados levantados e aqui apresentados, verificou-se que ser empreendedor vai muito além do que abrir seu próprio negócio. Para tanto, buscouse avaliar a autogestão, o capital social e a participação no empreendimento dessas mulheres. Verificou-se que a Associação está inserida num contexto de uma nova economia, a economia solidária, cujo principal objetivo é fortalecer uma base social que almeja, de forma coletiva, atender ao mercado e aos interesses dos envolvidos no trabalho, em que o bem de um é o bem de todos. Entretanto, na referida Associação, algumas características para um empreendimento neste formato darem certo, ainda estão em processo de desenvolvimento.

A primeira característica avaliada é o capital social. Verificou-se que este é a base de fundação da AMQSA; porém, o aprendizado para a autogestão precisava ter se mostrado mais efetivo por parte das mulheres, a fim de obter melhor resultado para o trabalho coletivo. Com isso, a participação enquanto característica de um empreendimento solidário ficou restrita ao processo de produção pela maioria das mulheres artesãs.

A última característica analisada foi a autogestão, cujos dados revelaram ainda estar distante de ser vivida pelas mulheres artesãs, tendo em vista que a própria forma de organização da Associação demonstra que a gestão é verticalizada, uma vez que a presidente transmite as informações sobre as decisões tomadas, determinando as atividades a serem realizadas pelas mulheres. Por outro lado, de acordo com as entrevistas realizadas com as associadas, não há motivação nem interesse, da parte dessas mulheres, participar mais das tomadas de decisões e da organização administrativa da AMQSA.

Diante dessa análise, acredita-se que, embora a autogestão, o capital social e a participação sejam essenciais para se construir um empreendimento solidário, antes da sua constituição, se faz necessário desenvolver, nas pessoas, capacidades para 
empreender, superando a cultura subalterna de submissão ao modelo de trabalho assalariado. Já as agências de fomento devem oferecer uma qualificação que atenda às suas necessidades e ao seu nível de conhecimento, buscando capacitar para o exercício de cargos e funções gerenciais/comerciais, através de uma linguagem que permita o diálogo. Por outro lado, falta um acompanhamento dos empreendimentos fomentados para avaliar o desenvolvimento das suas capacidades autogestionárias para renovar se necessário as qualificações aos beneficiados que demonstrarem um perfil de liderança. Finalmente, acredita-se que buscar uma orientação sobre as formas de relacionamento que priorizem valores da solidariedade na condução do negócio pode ser um grande diferencial para quem vai entrar num mercado cada vez mais tecnológico e competitivo.

\section{Referências}

BORDENAVE, Juan Diaz. O que é participação. São Paulo: Brasiliense, 1994.

BOURDIEU, Pierre, Le capital social: notes provisoires. Actes de Ia recherche en sciences sociales, Paris, n. 31, p. 2-3, janeiro de 1980.

COSTA, Delaine Martins. Práticas de empreendedorismo feminino: reflexões a partir de experiências multissituadas. In: SOUZA, Rosimere de; AZEVEDO, Patricia; COSTA, Delaine Martins (Orgs.). Políticas Públicas, empreendedorismo e mulheres: olhares que se encontram. Rio de Janeiro: IBAM, 2012, p. 15-45.

DALMORO, Marlom; WITTMANN, Milton Luiz e LEANDER, Luiz Klein. A presença de fatores geradores de capital social em organizações de natureza cooperativa. Revistas Sociais e Humanas. vol. 22, n.1, p. 1-20, 2009. Disponível em: < http://cascavel.ufsm.br/revistas/ojs-2.2.2/index.php/sociaisehumanas/ article/view/722>. Acesso em: 20 de outubro de 2015.

DOLABELA, Fernando. Pedagogia empreendedora. São Paulo: Cultura, 2003.

DORNELAS, J. C. A. Empreendedorismo na prática: mitos e verdades do empreendedor de sucesso. Rio de Janeiro: Elsevier, 2007.

FECOMERCIO. Avanço da tecnologia influencia cada vez mais as relações de trabalho. Disponível em: $<$ http://www.fecomercio.com.br/noticia/avanco-da-tecnologia-influencia-cada-vez-mais-as-relacoes-detrabalho>. Publicado em 29/10/2015 e acessado em: 11 de novembro de 2017.

GAIGER, L. I.; CORREA, A. S. O diferencial do empreendedorismo solidário. Ciências Sociais Unisinos, v. 47 , n. 1, p. $34-43,2011$.

GEM - Global Entrepreneurship Monitor. Empreendedorismo no Brasil: 2016. Curitiba: IBQP, 2017.

GOMES, Daniel Teodoro; GUERRA, Paulo Vítor; VIEIRA, Bruna Nobre. O Desafio do Empreendedorismo Feminino. Anais do XXXV Encontro da ANPAD. Rio de Janeiro: ANPAD, p. 1-17, 2011. Disponível em http://www.anpad.org.br/admin/pdf/EOR1980.pdf. Acesso em: 11 de novembro de 2017.

GUTIERREZ, Gustavo Luiz. Autogestão de empresas: considerações sobre um modelo possível. Revista Administração de Empresas. Rio de Janeiro, 1988.

HELlWIG, Beatriz Centenaro, CARRION, Rosinha Machado. A participação no processo decisório: um estudo na economia solidária. Revista de Gestão USP, São Paulo, v. 14, n. 4, p. 1-14, outubro/dezembro 2007

IBGE. Lucena. Dados gerais. Disponível em <http://cidades.ibge.gov.br/xtras/perfil.php?codmun $=250860>$. Acesso em: 26 de julho de 2017 . 
LAKATOS, Eva Maria. Fundamentos de metodologia científica. 6. ed. São Paulo: Atlas, 2007.

PNAD - Distribuição de pessoas desocupadas por idade, $3^{\circ}$ trimestre de 2017. Disponível em: <https:// www.ibge.gov.br/estatisticas-novoportal/sociais/educacao/9173-pesquisa-nacional-por-amostra-dedomicilios-continua-trimestral.html? \&t=destaques $>$. Acesso em: 10 de outubro de 2017.

POLANYI, K. A grande transformação: as origens da nossa época. 2.ed. Rio de Janeiro: Campus, 2000.

PORTES, Alejandro. Capital Social: origens e aplicações na sociologia contemporânea. Sociologia, Problemas e Práticas, ${ }^{\circ} 33$, p. 133-158, 2000.

SCHUMPETER, Joseph A. Teoria do desenvolvimento econômico: uma investigação sobre lucros, capital, crédito, juro e o ciclo econômico. São Paulo: Abril Cultural, 1982.

BEDÊ, Marco Aurélio (Coord.). Os donos de negócio no Brasil: análise por sexo (2003-2013). Brasília: SEBRAE, 2015. [Série Estudos e Pesquisas]. Disponível em: <http://www.bibliotecas.sebrae.com.br/ chronus/ARQUIVOS_CHRONUS/bds/bds.nsf/4b813ba67e266bbdc48177dd04726c87/\$File/5452.pdf>. Acesso em: 13 de outubro de 2017.

ZAHIDI, Saadia, LOPEZ-CLAROS, Augusto. Empoderamento das mulheres: avaliação das disparidades globais de gênero. WORLD ECONOMIC FORUM. 2005. Disponível em: <file://C:/Users/Patricia/ Downloads/empoderamento_mulher\%20(1).pdf $>$. Acesso em: 15 de outubro de 2017. 